\title{
Globalization and the "Temporal Turn": Recent Trends and Issues in Time Studies
}

\author{
Robert Hassan*
}

\begin{abstract}
Since at least the early 1990s there has occurred what might be termed a "temporal turn" within much of the social sciences and humanities. This was in some ways a reaction to an earlier turn that emanated from the late1970s-the "spatial turn," in which the processes of globalization were analyzed in largely spatial terms by an influential group of social geographers. The new emphasis on the nature of temporality was seen by many of its practitioners as a rebalancing of what had become an out-of-kilter space-time equation within the academe. Notwithstanding the tremendous contribution made by an emergent school of time scholars, the objective of the new focus on time needs to serve as a complement to the indissolubility of space-time as an immensely rich perspective through which to understand the dynamics of the economy, society, and the subjectively lived life.
\end{abstract}

Keywords: time, temporality, globalization, information society, Internet, social theories of time

\section{INTRODUCTION}

It is to be hoped that these thoughts and observations will go some way toward an increased recognition of a vast and growingly important issue in these first decades of the twenty-first century: the ways in which we relate to time and temporality, both as individuals and as part of a complex and interconnected global society. Time is, of course, already important in our lives and in our social world, but it is so in an essentially banal way that we can all readily appreciate. This commonplace relationship

* Robert Hassan is senior research fellow in the Media and Communications Program in the School of Culture and Communication at the University of Melbourne, Australia. He has written widely in the areas of temporality, new media, politics, and political economy. His most recent book is Empires of Speed (2009). Currently he is completing another monograph, The Age of Distraction, which will appear in 2011. E-mail: hassanr@ unimelb.edu.au

Manuscript received June 10, 2010; out for review June 20, 2010; review completed August 10, 2010; accepted August 20, 2010.

The Korean Journal of Policy Studies, Vol. 25, No. 2 (2010), pp. 83-102.

(C) 2010 by the GSPA, Seoul National University 
tends to obscure the central human relationship with temporality. For example, the time of the clock still acts as backdrop to our lives, scheduling and organizing our days and society's larger rhythms into a meter within which the world seems to work in the rational and modern way that our Enlightenment forebears said that it must. So ingrained has the clock time habit become, since at least the time of the Industrial Revolution, that we often imagine that this is what time is-despite the fact that in our lives and in our experience of it, time can appear to speed up or slow down in ways that we find difficult to articulate. However, there is rather more to time than the mere technological measure of duration-which is essentially what clock time is. Temporality, or varying forms and rhythms of time, are, as Bruno Latour has argued, "enfolded" and enmeshed into every facet of biological life, at both the micro and macro scaleand are in constant interaction between these polarities (Latour Latour, 2002, 249).

In late 2008, the immanently personal and global significance of time was brought home to almost all of us, at the micro as well as the macro level, in the form of the sudden irruption of the global financial crisis. At its symptomatic level of mortgage defaults, banking liquidity crises, massive lending exposures, and, finally, government bail-out packages to shore up a seemingly imploding financial system, the global financial crisis looked to many to be nothing more than a particularly virulent bout of capitalism's age-old and recurring boom-and-bust cycle; indeed, more than one economist argued that fallout from the crisis should be allowed to run its course in order to regenerate and revive the system through purely market mechanisms. However, underneath the massive figures of monetary loss, the general perception of government cluelessness regarding what to do, and the widespread public fury at the role played by Wall Street, time (or capitalism's particular relationship with it) was and is at the very core of the problem. The global financial crisis was in fact, at its root, an expression of the severe and ultimately intractable space-time crisis of accumulationthat is to say, of capitalist profitability (Jessop 2007). This view reflects a temporalized political economy perspective that emphasizes the fact that the planet is spatially finite in the context of an economic system based upon unlimited and unending growth and expansion - and that this leads to competitive pressures that force innovation and technological development to ever-faster speeds across every sector in the ongoing quest for efficiency.

The pressures of this crisis, both economic and political, came to a head in the mid1970s and saw the basis for the construction of a newly evolving form of capitalism over the ensuing decades. The surface manifestation of the spatial-temporal crises was the mutually reinforcing processes of a market-based form of globalization, and the information and communication technology revolution that profoundly shapes our world to this day. A fuller accounting of the space-time component of crises that are at 
the root of the global financial crisis is outside the scope of this paper and has been discussed elsewhere (Hassan 2010). It is significant, however, that the post-1970s economic, social, and technological solution to the space-time crises of capitalism acted as catalyst in the social sciences for a new appreciation of the function of temporality in the modern (or increasingly postmodern) world. It forms the intellectual contours of what may be seen as the temporal turn that I will now trace in outline.

\section{GLOBALIZATION AND THE PRODUCTION OF SPACE}

In order to understand the turn toward a more direct engagement with the nature of temporality in the social sciences, it is necessary first of all to consider the context in which it took place. As just noted, the space-time crises of the 1970s directed a new spatio-temporally informed perspective with which to comprehend how planet-wide transformation (technological, social, and economic) was occurring. However, the new orientation was largely one-dimensional, concerning itself primarily with questions of space. In many ways this was understandable. That these changes were characterized as globalization meant that theorists, economists, policy makers, and others tended to distill issues concerning the globe to those of space only. This, it would appear, makes for easier, if reductive, conceptualizations. After all, when we think of the world as a physical entity, it is attractively undemanding to slip into the language of the spatial - that, for example, of distance, territory, market share, and the problematizing of politically sovereign space (such as Kenichi Ohmae's 1990 "borderless world" thesis). But what this spatializing of the issue of globalization did, above all else, was to distort key elements of the process at the level of its baseline assumptions. As a direct consequence of this, a form of spatialized thinking permeated the discourse, and it underscored many of the great globalization debates that occurred in the 1980s and later (for example, Tomlinson 1991; Greider 1997; Pieterse 2000). We see this default tendency still in such concepts as a shrinking world and in the final arrival of the McLuhanesque global village through the rise of the Internet (McLuhan 1964). Moreover, the spatial analysis is commonly used as a way to understand the rise of the Asian tiger economies, viewing their development as constituting a profound spatiopolitical reconfiguration of what is termed the "global space economy" (Dicken 1994, 101-28).

The inspiration for much of this spatial theory emanated from the humanities. For example, in 1974 Henri Lefebvre published, to enthusiastic if largely francophone acclaim, his La production de l'espace. In it he developed the argument that permeated almost all his work, which is that space is a social product and that the production 
of urban space in particular is the basis for the reproduction (and spatial growth) of capitalism as an economic and social process. A growing interest in the book saw it translated into English and published by Verso as The Production of Space in 1990. The book enabled the spatial perspective on concepts of globalization to become more preponderant in the English-speaking academy. For example, Edward Soja applied Lefebvre's spatial theory to a key text in the spatial turn that he published as Postmodern Geographies in 1989. The book's subtitle, The Reassertion of Space in Critical Social Theory, expresses its mission unambiguously. For Soja, the "socio-spatial dialectic" that he imbibed from Lefebvre needed to be encouraged in the academy in order to reassess, or as he phrases it, to "deconstruct and recompose the rigidly historical narrative [and] to break from the temporal prisonhouse of language . . . and conventional critical theory" (Soja 1989, 1-2). Despite the book's limited appreciation of what constitutes time, as narrative time and as historical (chronological) time, his "reassertion of space" (at the expense of a subordination of time) was successful and influential; the book went into at least eight impressions, the latest in 2003.

Sharing an enthusiasm for the Lefebvrian viewpoint, and to similarly influential effect, was Fredric Jameson. His 1991 book Postmodernism, or, the Cultural Logic of Late Capitalism, called for what he saw as a "new kind of spatial imagination" (36566). Standing somewhat obliquely on the shoulders of Lefebvre, Jameson also emphasized the social in the production and reproduction of the spatial. He observed that the spatial imagination can serve as a way of "confronting the past in a new way [and] reading its less tangible secrets off the template of its spatial structures" (366). As a cultural critic — but also, like Lefebvre, as a Marxist—Jameson deployed this insight in an important way. Whereas Soja concerned himself mainly with issues of geography (both human and urban), for Jameson the spatial imagination was of principal utility as a way of understanding late-modern capitalism. Echoing the point I made earlier regarding the limits to geographic space into which capital may be profitably channeled, Jameson observed that the recent (post-1970s) "discontinuous expansion of quantum leaps in the enlargement of capital" constitute capitalism's "penetration and colonization of hitherto uncommodified areas" (410). This was globalization by another name, and Jameson reduced it to its most elemental essence, which was first systematically described by Marx in volume one of Capital (ref). Following Marx, Jameson noted that this "quantum leap" of expanding capital, the spread of commodification into increasing registers of culture and society-including those that are innately inconsistent with it, such as the family, education, and social relationships-results in an exacerbated experience of alienation through the commercialized "social forms that [increasingly] govern experience" (Jameson 1991, 411).

Geographer Doreen Massey has also turned the intellectual components of the spa- 
tial turn to vital areas of concern, and to useful effect as well. Most well known is her conception of globalization through the prism of what she terms power-geometry (Massey 1993). This may be viewed as a kind of spatial political economy, and Massey used it to map social and political relations in both their historical and contemporary contexts. For Massey this spatial political economy functions as a way to render social relations open to a new kind of critique - one that is especially amenable to an understanding of what constitutes the globalization process. The social and economic relations of globalization are, of course, very dynamic, and economists and politicians often see this dynamism as positive and evidence of a flexible and innovative and booming economy (Tapscott 1996; Wolf 1997). However, for Massey the key driving force here was the concatenation of power within specific (and constantly shifting) spatial coordinates. The significance of the power-geometry thesis lies in the idea that "space is by its very nature full of power and symbolism, a complex web of relations of domination and subordination, of solidarity and cooperation" (Massey, quoted in Blomley 2001, 16). As a form of spatial political economy, the analysis made salient the elements not only of power, but also of its corollaries under capitalism, which are class and exploitation. Thus, due to the "power-geometry of time-space compression,"

different social groups and different individuals are placed in very distinct ways in relation to these flows and interconnections. This ... concerns not merely the issue of who moves and who doesn't, although that is an important element of it; it is also about power in relation to the flows and the movement. Different social groups have distinct relationships to this anyway-differentiated mobility: some are in charge of it more than others; some initiate flows and movement, others don't; some are more on the receiving end of it than others; some are effectively imprisoned by it. (Massey 1993, 61)

Note how Massey introduced the concept of time-space compression in this passage. The term was borrowed from David Harvey, our final theorist of the spatial turn. In The Condition of Postmodernity (1989), Harvey made what I see as the definitive and most influential contribution to a conceptualization of spatial categories with which to understand contemporary economy and society. Again, the influence of Lefebvre was present, but with the addition of a strengthening dimension through the use of Pierre Bourdieu's notion of the "habitus" (Harvey 1989, 218-19). The main emphasis throughout Harvey's corpus has been the behavior and the effects of capital accumulation within its historical and contemporary spatial formations. His insight is that capital must always seek to reconstitute itself, often in unpredictable ways due to its innate contradiction, wherein it must constantly expand within the context of finite geographic space. He explored this theme previously in The Limits to Capital (1982), 
Consciousness and the Urban Experience (1985a), and The Urbanisation of Capital (1985b). The idea of time-space compression emanated logically from these, and in The Condition of Postmodernity Harvey used it to conceptualize how shrinking space not only affects the ongoing processes of capital accumulation, but also impinges upon social and individual experience.

Harvey did not use the specific term "globalization." In the late 1980s there existed no real consensus regarding a conceptual label for the immense socioeconomic and technological changes that had been under way since at least the beginning of that decade. It was not until 1992 that Roland Robertson's book Globalization finally embedded "globalization as a problem" (8-32) in academic discourse, and some unanimity concerning a descriptor then began to take hold. Nevertheless, Harvey had already identified the core issue and key problem with his idea of time-space compression. His "reference to the concept" was meant to convey the idea of processes that "so revolutionize the objective qualities of space and time that we are forced to alter, sometimes in quite radical ways, how we represent the world to ourselves" (Harvey 1989,240 ). The concept is hugely important for our present-day understanding of both time and space. Harvey brought the experience of time-space compression down to the objective level of individual experience-and showed how the material world and its processes of development and change actually oblige us to see it in different ways.

The chapter in which Harvey introduced the idea was titled "The Time and Space of the Enlightenment Project." The argument focused on the effects of time-space compression upon modernity-which was and is the material and social consequence of the intellectual revolution of Enlightenment thought. For Harvey, modernity had reached a critical phase of maturity. So comprehensive had the domain of capital become that it enmeshed people and societies within its processes to an extent that was historically unprecedented. For Harvey, this maturation was the cause for the emergence of the "condition of postmodernity" - and all that this meant in terms of the need for a radical re-evaluation of the bases of both Enlightenment thought and modernity's forces of production and reproduction. Crucially, the social production of space had, at the individual level, become wholly subsumed by the production (the shrinking) of space at the level of the system. The time-space compression thesis argued that this process held also in terms of the social production of time-in the ways people experienced time, and how temporality metered the world. The postmodern systems of production, in other words, had begun to contribute to what Harvey saw as a "speed up in the pace of life" $(1989,240)$.

Here we reach something of a high point in our discussion of the spatial turn in the social sciences and humanities. The idea of the production of space, from Lefebvre to Harvey (with many thinkers in between) had thrown much critical light upon the 
dynamics that were shaping the modern (and postmodern) world, and on the new ways in which production, technological innovation, and society were dialectically developing. Many theorists of space also noted the effects of time, speed, and acceleration. But not enough attention had been given to questions of time and temporality and the transformed individual and social relationship with these. With the exception of Jameson, all the Lefebvre-influenced theorists had trained as geographers-the quintessential discipline of geometric and Euclidian rationale that conceives of the world and the worldview through spatial categories (Gare 1996, chapter 3). Lefebvre's "social production of space" thesis upset the ancient mathematics-based method; and, as just noted, the leading space thinkers did acknowledge the importance of the temporal category. However, disciplinary training and intellectual habit tended toward loading the weight of preponderance to the formally spatial at the cost of the temporal. Doreen Massey, for example, published an excellent book in 2005 that dealt with questions of space and time. However, it is not until the final chapter that she began to discuss time more systematically - and the book itself is revealingly titled For Space (2005). And Harvey, despite the tremendous potential within the time-space compression thesis, also gave much of the emphasis, and devoted much of his discussion, to questions of space. Noel Castree has similarly observed this tendency in the work of Harvey, noting that his "best-known books do not strongly thematize time, though they do say a lot about space" $(2008,61)$.

This frustration with a lopsided and often dualist treatment of space and time predates Castree's or this author's experience. It had been occurring in tandem with the spatial turn itself, and numerous though dispersed thinkers, as we shall see, were stressing the importance of time-albeit to smaller audiences and to correspondingly lesser intellectual effect.

\section{THE IMPORTANCE OF TIME-AS WELL AS SPACE}

The growing feeling that issues of temporality had been relatively neglected was expressed in an important collection of essays, Timespace, which appeared in 2001, edited by two geographers, Jon May and Nigel Thrift. The volume is valuable in two ways. First, May and Thrift recognized the need to move beyond the tendency to prioritize space over time, and to challenge what they saw as a "spatial imperialism" in the ways in which social theory and sociology (and indeed the discipline of geography) had developed since the 1970s (May and Thrift 2001, 2). Second, they argued that it would be a mistake to simply overturn the spatial imperialism thesis and replace it with a temporal one-and it would be a further mistake to seek to balance the equa- 
tion by just giving equal emphasis to both time and space. They sought to go beyond what they termed the "dualism in the foundational categories of Space and Time" in order to stress that "space and time are inextricably interwoven" (1-2). The full title of the collection, Timespace: Geographies of Temporality, expressed this aim, and the essays within, in varying ways, similarly reflected the inextricably interwoven concepts in topics ranging from politics and history to daily life and religion. As such, the volume constituted an important intervention into the issues surrounding time and space, and gave a new dimension to how they can be used as analytical frameworks in the social sciences and humanities.

What I want to do in what follows is to describe the salient contours of the temporal turn, but with the rider that, like May and Thrift, the summary is not developed in a way that seeks to redress or balance the time-space equation-but to accentuate the intrinsic and vital oneness of time and space, and to show that in order to understand one as a central concept in social life, we must understand both in their unity.

A logical place to begin a review of the elements of the emerging concern with time and temporality as a social and philosophical dimension of importance is with Norbert Elias's 1992 book Time: An Essay. As with Latour and his idea of time enfolding into everything, Lefebvre, who conceived of time as irreducibly social, and Heidegger, who wrote $(1972,16)$ that "there is no time without man," Elias's starting point for understanding time was recognition that time must first and foremost be something that is objectively experienced. For Elias it was the process of change and our ability to cognitively and reflexively experience it that constituted the starting point for an understanding of social time. This insight led him to a working definition of time. The experience of time, he observed, "is based on people's capacity for connecting with each other two or more different sequences of continuous changes, one of which serves as a timing standard for the other (or others)" (Elias 1992, 72). Elsewhere in the book, Elias expressed this concept within a slightly more expanded point of view: "the word 'time' is a symbol of a relationship that a human group of beings biologically endowed with the capacity for memory and synthesis, establishes between two or more continua of changes, one of which is used by it as a frame of reference or standard or measurement for the other or others" (46).

I have on the wall of my office a sheet of A4 paper upon which, in bold 44-point sans-serif type, there is a beautifully condensed summation of Elias's idea of the nature of social time. It was written by Simonetta Tabboni in a majestic essay, "The Idea of Social Time in Norbert Elias," and it reads: "The social construction of time ... goes back to a specific human ability to work on the experience of change, to react, to organize and confer meaning on the experience" (Tabboni 2001, 7; emphasis in original). In this reading, time can only be understood-properly and in its essence-as 
social time, created by humans in their social world and recognized as such because they are human. Uniquely as a species we impute meaning into things, and through meanings that are elicited from change we also generate the basis for the recognition of the process of time as change.

Admittedly, this is somewhat difficult to understand. This problem is nonetheless ironic, because social time, thus understood, forms the backdrop to our social lives, and we unconsciously navigate these temporal shoals of change every day. The difficulty, as already noted, stems from the fact that mechanical clock time displaces, disturbs, and clouds this awareness through the weight of its historical presence and through its continuing economic imperatives (Nowotny 1994). It is, nonetheless, worth cracking the theoretical nut of social time in order to consider its contents, so as to develop a better understanding of social time in practice.

In her essay on Elias, Tabboni noted that in the general literature on the origins of time awareness, "two types of awareness are indicated as central: that of continuity/ discontinuity and that of recurrence" $(2001,7)$. Considering the awareness of continuity and discontinuity, Tabboni wrote that these are "polar categories" but that they are defined in their opposition and are "only capable of consideration in their reciprocity." She went on to elaborate that we experience these "when we realize that a change has taken place in some part of our reality: in our body, in our thoughts, in the physical and social world around us" (7). Change is movement, and this is characterized, as Tabboni explained, by "events ... in relation to which one can see a before and after, something commonly referred to in expressions like 'from then on' or 'from that day on" (7). The idea of recurrence is equally fecund. This is "the regular cyclical return of the same phenomena: pulse beats, sleeping and waking, day and night, Christmas and Easter follow each other and provoke behavior that seems unchanging. The seasons of the year alternate with social seasons and give place to recurrences, not of events which can be seen as having a before and after" (8). Event-generated change and patterns of cyclical recurrence thus comprise the grids of temporal reference that constitute our temporal being. The fundamental elements that make time human, then, are the embedded temporalities both in our living bodies and in the natural world that surrounds us.

This perspective is admittedly still rather individualized and does not fully convey an impression of the actual social dimensions of social time, of people moving through a social world, constantly in interaction with others within shared environments. However, Lefebvre in The Production of Space (1990) made a move in this direction. In a tantalizing but ultimately undeveloped passage on time, he gave a lucid description of the temporal "rhythms" of the body that are "deployed" into what he calls "real' abstract" (or socially constructed) space: 
Rhythms in all their multiplicity interpenetrate one another. In the body and around it ... rhythms are forever crossing and recrossing, superimposing themselves upon each other, always bound to space. . . . if we attempt to specify them we find that some rhythms are easy to identify: breathing, the heartbeat, thirst, hunger, and the need for sleep are cases in point. Others, however, such as those of sexuality, fertility, social life, or thought are relatively obscure. Some operate on the surface, so to speak, whereas others spring from hidden depths. (Lefebvre 1990, 205)

As noted previously, the original French-language edition of Lefebvre's book was published in 1974. Its (scattered) gems on the nature of time helped to generate a literature that, from the time of Emile Durkheim (1892/1964) and Pitirim Sorokin and Robert Merton (1937), had still not become a proper school or movement, but was beginning to orient toward a broadly sociological and critical-theory approach to time (Sherover 1975; Cottle 1976; Hendricks and Hendricks 1976). Latour made social time a rather more significant aspect of his actor network theory, which is based on the interactive agency between networks of humans and technologies. Latour saw temporality (or the creation of social time) as part of the essential functioning of the actor network theory dynamic. Echoing the quote from Heidegger cited above, Latour maintained that "the connections among beings alone make time" and that only humans "have the capacity to produce both time and space." Latour went on to say that "it was the systematic connection of entities in a coherent whole that constituted the flow of modern time" (1993, 77; my emphasis).

All this moves us some way forward in our understanding of the social nature of time, and the foregoing few paragraphs constitute the basis any understanding of a sociology of time. Nevertheless, this discussion does not yet form a functionally robust framework that links the subjective experiences of time and their multiplicities (embedded in bodies and in nature) with the ongoing creation and emergence of time in everyday life situations. It does not yet promote the temporal dimension to the status of one that places all other dimensions of the social in a new and revealing light. To move to this level of synthesis, we need to consider the work of Barbara Adam. Adam achieved this fusion though the introduction of a new concept, which she termed "timescapes." It has been Adam's life's work to make salient the function of temporality from the perspective of sociology, and her 1998 book The Timescapes of Modernity contained the introduction of the concept and the initial systematizing of the supporting theory.

The "scape" in Adam's idea of "timescape" is significant. A scape is a scene or a view, and this suggests a strongly spatial element, which is evident in the everyday use of the term in compound words such as in seascape and landscape. One of Adam's 
signal contributions has been to integrate the spatial with the temporal through the timescape concept. As Adam put it:

Where other scapes such as landscapes, cityscapes and seascapes mark the spatial features of past and present activities and interactions or organisms and matter, timescapes emphasizes their rythmicities, their timing and tempos, their changes and contingences. A timescape perspective stresses the temporal features of living. (Adam 1998, 11)

The timescape, then, stresses the priority of the spatial-temporal whole in place of the historical dualism that has permeated our modernist thinking on time and space, and raises to prominence the dynamic of time in the always-emergent human condition. And so a cityscape, for example, in its living, growing, and changing form, is more than the spatio-geometry of its buildings, the grid or maze of its streets, alleys, and boulevards, or the serrated horizon of its skyline. The cityscape also throbs with the traffic that flows through its arteries; the machine rhythms of capitalism temporally mark the days with opening and closing times of businesses; and people swarm to the city to experience (and to create) its buzz of activity and its uncountable multitude of temporal diversity - from the fast-paced excitement of a nightclub, to the quiet and reflection of study in a public library. Adam highlighted the "symphony of rhythms and temporalities" in the production of social time $(1998,13)$. The metaphor of the symphony is apt. It illustrates the diversity of timescapes that can come together to create the temporal whole. In the social context, the kaleidoscope of timescapes "gives a dynamic structure to our lives that permeates every level and every facet of our existence" (13). Within this temporal framework "all aspects interpenetrate and have a bearing on each other. All coexist and are lived simultaneously," and this "underpins our development as humans and as living organism. It marks us as creatures of this earth, as beings that are constituted by a double temporality: rhythmically structured within and embedded in the rhythmic organization of the cosmos" (13).

When the idea of social time is spelled out like this, courtesy of penetrating and illustrative thinking such as that of Elias, Tabboni, and Adam, then the deeply temporal nature of our lives become more apparent and clear. We can see that we contribute to, and derive temporal experience from, the multitude of timescapes that comprise the taken-for-granted backdrop of time that we are so used to, and the theorized level of the abstract becomes apparent through the efforts of such social theorists. But therein lies the problem of an adequate understanding of social time in our modernist context: it needs a conscious theoretical effort to render it clearer. This is because the social in social time is not a pure, unadulterated entity. The social reflects our messy humanity, 
and its baleful proneness toward hierarchy, exploitation, the concentrations of power, and increasing layers in the complexity of life.

Lastly, it is this definition of time as irreducibly social that gives analytic power to the time-space compression thesis of Harvey - to make salient only one of the insights that the temporal turn has made possible. It enables us to reflect more accurately upon the speed-filled and speed-driven "objective qualities" of change as it emerged from the transformation from a modern productive mode based upon machines and factories and the socioeconomic accoutrements of Fordism that were metered by clock time, to a postmodern mode based upon flexibility, the rising dominance of information, and the accelerating meter of time created within digital networks (Harvey 1989, 141-73).

\section{TIME STUDIES TODAY}

A sure sign of the growing significance of an idea in our world is the emergence of popularized versions in the marketplace. And so it is with the idea of time and temporality. Since at least the beginning of the present decade, an emphasis upon time and a focus upon new ways of understanding and relating with it has seen the emergence what might almost be called a time genre. For instance, in 2001 James Gleick published Faster: The Acceleration of Just About Everything. Gleick is an American science writer with, as the book's dust-jacket blurb informs, "a healthy pop sensibility." Faster offered a highly accessible pop overview of the effects of our speed-stressed and time-stretched age. In a similar vein, published in 1999, was Englishwoman Jay Griffiths' Pip Pip: A Sideways Look at Time. As the title suggests, Griffiths has offered a witty and oblique look at the contradictions and conundrums that reside inside the notion that "while nature knows a million varieties of time, the clock of modernity knows only one" (Griffiths 1999, 15).

Translated from the German and published in 2007 was Stefan Klein's The Secret Pulse of Time. Klein, like Griffiths, sought to make sense of the seeming irrationality in the fact that "the rhythm of the day and night is programmed into humans at birth" but the societies we live in "structure our day in accordance with minutes and hours" (Klein 2007, 10). These books and others like them have expressed a modern frustration with our relationship with time and its apparent scarcity and stressfulness and anxiety-filling relentlessness. They ask fundamentally the same question: how do we stop this and arrive at a more harmonious relationship with both biological time and the seeming necessity for the machine time that organizes us rationally into coherent societies? Ultimately these approaches fail because they do not (or cannot) direct a critical consciousness toward the deeper questions of time in a way that is accessible 
(beyond the surface level) and also sellable. The need to avoid difficult theoretical questions for marketing purposes means that they inevitably fall into mere description that is leavened by a veneer of science, or humor, or a journalistic sensibility. The effect is, again inevitably, that we close such books after reading — and promptly forget them. This is a pity, because they tantalize with the mental pictures they paint, but then don't allow us an explanation of what actually makes these pictures likely.

It is still possible to make some conceptual headway, though. A popular novel that seemed to make some impression upon a critical time consciousness was Sten Nadolny's 2003 The Discovery of Slowness, the translation of a 1983 German-language original. The book is a fictionalized account of the real-life nineteenth-century explorer Sir John Franklin. The book's power lies in its device of imputing a kind of slowness into the character of Franklin, which set him apart from the normal rhythms of speaking, thinking, and acting that pervaded his Victorian society. As a consequence, Franklin's contemporaries were not sure if this character trait was the mark of genius and the comportment of a hero- or if he was simply a fool. His friends, enemies, and acquaintances thus never really get the measure of him in ways that they could use to understand or exploit him. The book and its subject of slowness was the inspiration for a number of television programs, exhibitions, and at least one film. In Germany especially, the book was extremely popular and spurred numerous seminars in business and business administration that explored the possibilities of slowness (instead of unthinking speed) in the corporate world.

Such exceptions aside, though, reflective and critical appraisals of time remain within the confines of the academe still—and it is here that our summary will conclude. Academic books are still the most useful way to get a feel for the evolving perspectives on time in the social sciences. An excellent (and influential) primer in this field is G. J. Whitrow's What is Time? (1972/1989). Ranging across the history and science of timekeeping, Whitrow strove to remind us that notwithstanding the dominance of mechanical ways of "keeping" time, time has always been able to be experienced in other ways, and that these ways must continually be explored and debated. A constant figure in the generalist accounts on the nature of time, at least since the mid-1960s, has been J. T. Fraser. In 1966 Fraser founded the International Society for the Study of Time, which continues to hold triennial conferences around the world that attract a wide diversity of perspectives on time across an equally wide field of subjects, from music and art to science and society. Fraser himself has written prodigiously; his books include The Genesis and Evolution of Time (1982), Of Time, Passion, and Knowledge (1990) and Time and Time Again (2007). A major time scholar we have met already is Barbara Adam. A German who has lived in Wales since the 1960s, Adam is a true pioneer in the study of time, especially as it related to sociological questions, environ- 
mental issues, and how we can relate to the future, both as individuals and as part of society. Adam's timescape concept from her book Timescapes of Modernity (1998) remains the weight-bearing foundation of all of her work. Her 2004 book Time is probably the most incisive generalist account of temporality available, and accompanies Whitrow's book as a landmark publication.

More subject-specific work is being undertaken with an increasing number of scholars utilizing the wider literature to illuminate their own professional pathways. Alan Bluedorn, for instance, has focused his skills as a time scholar on the problems, issues, and opportunities of the business world, more specifically in business organization. He argued insightfully in The Human Organization of Time (2002) that time is change, and the organization that does not change when it needs to (through a timely understanding the wider rhythms of change that affect its environment) will run into trouble or fail (126).

Hartmut Rosa has concentrated on an altogether different theme. He used a mix of temporally oriented philosophy and sociology to study what he termed "social acceleration" in his contribution to a 2009 collection, High-Speed Society. In it Rosa, for the first time, attempted to provide empirical evidence for the argument (or theory) that life seems to speed up. Using Gleick's book as a foil, Rosa showed how we can actually measure acceleration through different indexes of social change (2009, 77-112). Rosa's co-editor in this collection was William Scheuerman, who previously penned a pathbreaking book called Liberal Democracy and the Social Acceleration of Time (2004). Scheuerman is a political scientist, and in this book he directed his temporal analysis to the rhythms of politics: the time of political action, political philosophy, and legislative change, since at least the era of the Enlightenment. He concluded that life (social, cultural, and economic) is now running too fast for a liberal democratic politics that was conceived in a different age and reflected the rhythms of that much slower age. Relatedly, Kimberly Hutchings, in her book Time and World Politics (2008), reflected upon international politics through the lens of temporality. What she termed a "world-political time" is a form that has evolved, she argued, through a closed reading of the philosophy of history that emphasized the mechanical metaphors that, from the time of Plato, entrenched a western universalism as the fundamental clock-centered political model that disavows any concept of "multiple co-existing presents" (21).

However, it is through academic journals that the front-line of intellectual inquiry is pursued in the field of time studies. As with any discipline or field, the peer-reviewed journal gives latitude to the ambitious idea and the adventurous concept, and acts as the platform for the debates and disputes that push forward the epistemological boundaries of what we know as a society and how we understand and relate to our world. To 
conclude this essay, I will mention two relevant journals. The first is Kronoscope, a now-vintage periodical that was founded in 1966 by J. T. Fraser. According to its Web site, "The journal is dedicated to the cross-fertilization of scholarly ideas from the humanities, fine arts, sciences, medical and social sciences, business and law, design and technology, and all other innovative and developing fields exploring the nature of time" (Kronoscope 2010). This sums up very well the field of vision that the journal opens up for itself; indeed, this is indicated in the cleverness of its title. Kronoscope is published twice a year and is currently edited by Marlene Soulsby. It is the publishing organ of the International Society for the Study of Time and hosts in print the debates and the interests of its members. As its Web site states, the journal's interests reflect the ubiquity and diversity of the temporal in human affairs, and so much of what it deals with can be rather esoteric - in the best possible sense that it probes and forages where no-one else does. But this is not always so, and a recent issue edited by Ida Sabelis on the subject of Time, Organization and Management dealt incisively with the temporal realities that underpin everyday life in the world of business (Sabelis 2009).

The second journal, Time and Society, is one I can comment on with rather more authority. I have been its editor since 2005, and have been joined as co-editor since 2008 by Hartmut Rosa. Like Kronoscope, our mission is to promote the subject of time as one of infinite value in the understanding of human affairs, and to make as salient as possible the idea that we-as scholars and as individuals - have given too little consideration to a humanly and socially constructed process that affects all of us deeply, both at the level of individual phenomenological experience (in all its changing and individuated diversity), and at the level of the system (that of the institutions that organize society, and the capitalist logic that shapes so much of it on an interconnected and globalized scale). Barbara Adam, who served as its editor until 1998, founded the journal in 1992. Adam's objective was encapsulated in an essay she published in the journal's second issue. On the nature of time, she wrote that although it is

deeply taken for granted in our daily lives and our social theories, it is not easily accessible to conscious reflection and social science analysis. This means that time needs to be made visible before its pervasive role in modernity can be appreciated. (Adam 1992, 175)

In setting the standard, Adam has over the years motivated some landmark interventions from a wide range of subjects. There are many in the journal (and yes, as editor I would say that), and I will here relate only a couple. In 1996 Klaus Kummerer published "The Ecological Impact of Time." In it he concentrated perceptively in the tem- 
poral aspects of the chlorofluorocarbon debates that were flaring at that time. The broad scope of his temporal approach to the "socio-environment," however, remains applicable today in the somewhat more serious processes of global warming. And so Kummerer warned of the necessary time orientation that policy makers and scientists must have in order to respond to industrial-ecological processes. The following statement remains disturbingly cogent:

Because of the requirement of incontrovertible proof of undesirable and unexpected consequences must first be given before people are prepared to negotiate, the dimension of time is excluded from the considerations, and hence the time for (proactive) negotiation is thrown away. (Kummerer 1996, 213)

Another vast wheel of human transformation, this time in the form of the Internet, was temporalized in another standout essay, by Heejin Lee and Jonathan Liebenau in 2001. The Internet, they wrote, marks a new technological mode for the production and experience of time. The Internet, indeed, is a "contemporary analogue" of the clock that has governed industrialized societies for over 200 years. The analogue, however, is digital, and is not fixed and unerring as is the strictly measured tick of the clock. Lee and Liebenau's key point, however, is that "the impacts of information technology on time assume different patterns depending on the stages in the development of information technologies" (Lee and Liebenau 2001, 49; my emphasis). Internet time, then, is flexible, unpredictable, and (like the Internet itself) dependent upon the caprices and volatilities of the neoliberal capitalist system that shapes and directs its development. The essay spoke to a very Jacques Ellul-like loss of technological control through the Internet (Ellul 1964). But if, as they insisted, we have a sufficiently developed sense of social time, we can see also that loss of technological control constitutes a (further) loss of temporal autonomy.

To finish, I will highlight an additional positive development in time studies, the emergence of new work from Asia with a focus on Asia. In 2006 the journal printed a special section on Time in Japan. Of course, the universal clash between individual and cultural experience of time and the mechanical clock time of modernity was readily apparent there as well. The issue contained excellent essays from three Japanese time theorists, Masae Yuasa, Yokho Tsuji, and Sachiko Kaneko. These ethnographic accounts of the timing of daily life in Japan showed how locally produced time can have its own culturally formed rhythms and culturally shaped effects. A common theme to emerge from the essays was that despite the famed Japanese penchant for punctuality, there is underneath this mechanical rhythm of business and much of life a seething diversity of rhythms in play, each produced in its local context and having its 
own specific qualities, both positive and negative. In the same issue, Brigitte Steger highlighted this in the form of what she described as a cultural accommodation with the rhythm of modernity, in her fascinating discussion of the practice of inemuri, in which students who sacrifice some night-time sleep in order to study late make up for this biorhythmic lack by taking a nap in the afternoon, a practice that is widely tolerated in Japan but sits less well with the Anglo-Saxon work ethic (Steger 2006, 197-214). All these perspectives are, of course, a necessary re-emphasizing of the universal diversity of social time-and a restatement of its constantly contingent interrelationships with economic and technological change. Within the interstices of such common cultural experiences of time, some of the most valuable work is currently being undertaken.

\section{CONCLUSION}

Notwithstanding the huge strides taken by theorists of time in philosophy and in the social sciences, we are still in our infancy in terms of understanding its nature and how we relate to it, produce it-and live it. The problem of our underdevelopment, however, goes far beyond the academe. Long ago St. Augustine wrote what has become a byword for our confrontation of the issue of time: "What then is time? If no one asks me, I know what it is. If I wish to explain it to him who asks, I do not know." Time is everywhere and in everything, but has the slippery quality, as Adam put it, of "being not easily accessible to conscious reflection." Conscious reflection, in the age of high-speed telecommunications, the Internet, "information overload," multitasking, texting, and tweeting is, to say the least, becoming less easy. However, unless we consciously make the time to consciously reflect, we run the grave risk of becoming further in thrall to technological time, both to clock time and increasingly to the times of a globalized digital network that is oriented toward speed and efficiency and is corrosive of the social in social time - that is to say, that which we experience, and hopefully that which we can more consciously reflect on.

\section{REFERENCES}

Adam, B. 1992. Modern times: The technology connection and its implications for social theory. Time and Society, 1: 175-92. 1998. Timescapes of modernity: The environment and invisible hazards. London: Routledge. . 2004. Time. Cambridge: Polity. 
Blomley, N. 2001. Landscapes of property. In N. Blomley, D. Delaney, and R. T. Ford (Ed.), The legal geographies reader: Law, power and space (pp. 118-29). Oxford: Blackwell.

Bluedorn, A. 2002. The human organization of time: Temporal realities and experience. Stanford: Stanford University Press.

Castree, N. 2008. The time-space of capitalism. Time and Society, 18(1): 26-61.

Cottle, T. J. 1976. Perceiving time: A psychological investigation with men and women. New York: Wiley.

Dicken, P. 1988. Global local tensions in the global space economy. Economic Geography, 70(2): 101-28.

Durkheim, E. 1892/1964. The division of labour in society. New York: Free Press.

Elias, N. 1992. Time: An essay. Oxford: Blackwell.

Ellul, J. 1964. The technological society. New York: Knopf.

Fraser, J. T. 1982. The genesis and evolution of time: A critique of interpretation in physics. Amherst: The University of Massachusetts Press.

1990. Of time, passion, and knowledge: Reflections on the strategy of existence. Stanford, CA: Stanford University Press. . 2007. Time and time again. Leiden: Brill.

Gare, A. 1996. Nihilism Inc. Sydney: Eco-Logical Press.

Gleick, J. 2001. Faster: The acceleration of just about everything. New York: Abacus.

Greider, W. 1997. One world, ready or not. New York: Simon \& Schuster.

Griffiths, J. 1999. Pip pip: A sideways look at time. London: Flamingo.

Harvey, D. 1982. The limits to capital. Cambridge: Blackwell. . 1985a. Consciousness and the urban experience. Oxford: Blackwell. 1985b. The urbanisation of capital. Oxford: Blackwell. 1989. The condition of postmodernity. Cambridge: Blackwell.

Hassan, R. 2009. Empires of speed. Leiden: Brill.

. 2010. The speed of collapse: The space-time dimensions of capitalism's first great crisis of the 21st century. Critical Sociology, 23(3): 270-92.

Heidegger, M. 1972. On time and being. New York: Harper and Row.

Hendricks, C. D., and J. Hendricks. 1976. Concepts of time and temporal construction among the aged. In J. F. Gubrium (Ed.), Time, roles and self in old age (pp. 533-46). New York: Human Sciences Press.

Hutchings, K. 2008. Time and world politics. Manchester, UK: Manchester University Press.

Jameson, F. 1991. Postmodernism, or, the cultural logic of late capitalism. London: Verso.

Jessop, B. 2007. What follows neo-liberalism? The deepening contradictions of US 
domination and the struggle for a new global order. http://eprints.lancs.ac.uk/ $1005 /$.

Kaneko, S. 2006. Japan's socially withdrawn youths and time constraints in Japanese society. Time and Society, 15(2/3): 233-50.

Klein, S. 2007. The secret pulse of time. Melbourne: Scribe.

Kronoscope. 2010. http://brill.publisher.ingentaconnect.com/content/brill/kro

Kummerer, K. 1996. The ecological impact of time. Time and Society, 5(2): 219-35.

Latour, B. 1993. We have never been modern. Cambridge, MA: Harvard University Press.

2002. Morality and technology. Theory, Culture \& Society, 19(5/6): 247-60.

Lee, H., and J. Liebenau. 2001. Time and the Internet. Time and Society, 9(1): 43-56.

Lefebvre, H. 1990. The production of space. Oxford: Blackwell.

Massey, D. 1993. Power-geometry and a progressive sense of place. In J. Bird et al (Ed.), Mapping the futures: Local cultures, global change. New York: Routledge.

Massey, D. 2005. For space. London: Sage.

May, J., and N. Thrift. 2001. Introduction. In J. May and N. Thrift (Ed.), Timespace (pp. 1-46). London: Routledge.

McLuhan, M. 1964. Understanding media. New York: McGraw Hill.

Nadolny, S. 2003. The discovery of slowness. Edinburgh: Canongate.

Nowotny, H. 1994. Time: The modern and postmodern experience. Cambridge: Polity Press.

Ohmae, K. 1990. The borderless world. New York: Harper Perennial.

Pieterse, J. 2000. Global futures: Shaping globalization. London: Zed Books.

Robertson, R. 1992. Globalization: Social theory and global culture. London: Sage Publications.

Rosa, H. 2009. Social acceleration. In H. Rosa and W. Scheuerman (Ed.), High-speed society: Social acceleration, power, and modernity (pp. 77-112). University Park: Pennsylvania State University Press.

Sabelis, I. 2009. Introduction. Kronoscope, 8(2).

Scheuerman, W. E. 2004. Liberal democracy and the social acceleration of time. Baltimore: Johns Hopkins University Press.

Sherover, C. M. 1975. The human experience of time. New York: New York University Press.

Soja, E. 1989. Postmodern geographies. London: Verso.

Sorokin, P., and R. Merton. 1937. Social time: A methodological and functional analysis. American Journal of Sociology, 42(5): 615-29.

Steger, B. 2006. Sleeping through class to success: Japanese notions of time and diligence. Time and Society, 15(2/3): 197-214. 
Tabboni, S. 2001. The idea of social time in Norbert Elias. Time \& Society, 10(1): 5-27. Tapscott, D. 1996. The digital economy. New York: McGraw-Hill.

Tomlinson, J. 1991. Cultural imperialism. London: Pinter Publishers.

Tsuji, Y. 2006. Railway time and rubber time: The paradox in the Japanese conception of time. Time and Society, 15(2/3): 177-96.

Whitrow, G. J. 1972/1989. What is time? London: Thames and Hudson.

Wolf, M. 1997. Why this hatred of the market? Financial Times, May 3.

Yuasa, M. 2006. Time for housework and time for "oshigoto": Japanese housewives in a network business. Time and Society, 15(2/3): 215-34. 